\title{
SPESS: A New Instrument for Measuring Student Perceptions in Earth and Ocean Science
}

\author{
Alison Jolley, ${ }^{1}$ Erin Lane, ${ }^{1, a}$ Ben Kennedy, ${ }^{2}$ and Tom-Pierre Frappé-Sénéclauze ${ }^{3}$
}

\begin{abstract}
This paper discusses the development and results of a new tool used for measuring shifts in students' perceptions of earth and ocean sciences called the Student Perceptions about Earth Sciences Survey (SPESS). The survey measures where students lie on the novice-expert continuum, and how their perceptions change after taking one or more earth and ocean science course(s). The survey is composed of 29 statements that have been validated with expert responses and student interviews. Factor analysis was used to group statements into seven categories, which provide instructors with valuable information to guide pedagogical change in their classes. Overall student perceptions in earth and ocean sciences show little change over the course of the term, in contrast to novice shifts in perceptions seen in other science disciplines. Students in earth and ocean sciences also do not display any gender differences, unlike those seen in these other disciplines. However, differences are seen between face-to-face and distance education versions of a course, between earth and ocean science majors and nonmajors, and between a community college and a large research institution. The former of each pair are more expert-like. (c) 2012 National Association of Geoscience Teachers. [DOI: 10.5408/10-199.1]
\end{abstract}

Key words: student attitudes, student perceptions, student motivations, student beliefs, academic performance, classroom assessment, survey tool, survey design, validation

\section{INTRODUCTION}

One of the main goals of an undergraduate education is to move students from novice-like thinking towards expertlike thinking. Not only does this mean gaining knowledge of facts and concepts, but also changing perceptions of the disciplines studied in terms of how they are used and learned. In earth and ocean science, the Geoscience Concept Inventory (GCI) is one example of an instrument that can be used to measure the former (Libarkin and Anderson, 2005). While some surveys have been used to measure student perceptions towards earth and ocean science in grade school (e.g., Mao and Chang, 1998), no validated survey has been developed to measure general perceptions towards the discipline at the postsecondary level.

Here we report on the development of the Student Perceptions about Earth Science Survey (SPESS) to measure student perceptions (Appendix A). The SPESS is based on a perception survey developed by researchers in physics education, the Colorado Learning Attitudes about Science Survey (CLASS), which is appropriate for majors and nonmajors across all subdisciplines of physics (Adams et al., 2006). The CLASS is now widely used internationally, and has since been adapted for the Chemistry, Biology and Geoscience Departments at the University of Colorado (Barbera et al., 2008; W. Adams, pers. comm.).

Received 24 August 2010; revised 26 May 2011; accepted 26 July 2011; published online 16 February 2012.

${ }^{1}$ University of British Columbia, Carl Wieman Science Education Initiative, Earth and Ocean Sciences, 6339 Stores Rd., Vancouver, British Columbia V6T 1Z4, Canada

${ }^{2}$ University of Canterbury, Department of Geological Sciences, Christchurch, Canterbury 8140, New Zealand

${ }^{3}$ The Pembina Institute, 55 Water St., Vancouver, BC V6B 1A1 Canada

${ }^{a}$ Author to whom correspondence should be addressed. Electronic mail: elane@eos.ubc.ca. Tel.: 604-822-2138. Fax: 604-822-6088.
The main goals devised for the development of the SPESS are to (1) establish students' beliefs about the nature and relevance of earth and ocean science, (2) determine whether students perceive earth and ocean sciences the same way that experts in the field do, and (3) reveal the effects of course innovations on student perceptions and interest.

Previous surveys have been developed in order to measure student perceptions toward science in general (e.g., Fennema and Sherman, 1976; Aikenhead and Ryan, 1992; Libarkin, 2001; Lederman et al., 2002); however, they have different goals than the SPESS. The statements that are found on the SPESS and CLASS are specific to a discipline (earth and ocean science or physics). When these statements are phrased as pertaining to science rather than the discipline, students do not know how to answer (Adams et al. 2006). For example, when asked if they agree or disagree with "Understanding science basically means being able to recall something you've read or been shown," students reply, "It depends on whether you mean biology or physics." Thus, views of science in general are not specifically addressed in the SPESS; just the perceptions and beliefs towards the broad field of earth and ocean science are the focus of this survey.

The above goals have been used to guide the overlying research questions for the survey. Namely, what are students' perceptions about the nature and relevance of earth and ocean science in relation to those of an expert? Do these perceptions change over the course of a term, and if so, are there different groups of people (e.g., males vs. females) or different instructional styles (e.g., face-to-face vs. distance education) that show different results?

The source of students' personal beliefs is typically their experiences in schools prior to postsecondary and experience in their out-of-school lives (Gal et al., 1997). The nature of these classroom experiences (e.g., style/quality of instruction) can help predict student performance alongside previous math and science scores (Tai et al., 2006). Student 
beliefs about the nature of a discipline impact (1) "process considerations," or how students approach learning, (2) "outcome considerations," or how they translate their understanding to the world outside of the classroom, and (3) "access considerations," whether or not they choose to continue on in their studies of a discipline (Gal et al., 1997). Perceptions correlate with what courses a student chooses to take, and students' conceptual learning gains in these courses (Perkins et al., 2005). Thus, a general goal of education is to have students come to perceive the discipline more like an expert in the field, which in turn should lead to improved learning gains.

Experts not only have greater conceptual knowledge of the discipline, but they also hold very different views about how new knowledge is gained, structured, and manipulated. Hammer (1994) reviewed the literature that discusses the differences between novice and expert beliefs about science in the context of physics with regards to: (1) the structure of knowledge, (2) the content of knowledge, and (3) the source of knowledge. First, experts see knowledge within a discipline as comprising one coherent unit, and can usually rederive things if forgotten, or solve problems with a different approach (often many). Novices do not see this coherence, and think of the discipline as a grouping of separate pieces. They believe that to know these pieces is simply to remember them (Chi et al., 1981). Second, experts think that knowledge is made up of concepts that can be represented by equations, much like another language. They find this language to be fully translatable, and often common sense-like. Problems are solved by conceptualization. Novices think that knowledge is made up of facts and equations, which are not a representation of concepts or words. Problem solving is guided by searching for the correct equation, and then computing the answer mathematically (Larkin, 1983). Finally, experts believe that the acquisition of knowledge is an independent process (which is possible without an instructor), and making sense of the ideas is extremely important. They want to understand these ideas, and not just memorize them. Knowledge represents the real world. Novices believe that knowledge is handed down from positions of authority and learning is only remembering what they have been told. Knowledge is isolated and the representation of the real world is not apparent (Kitchener and King, 1981). While the SPESS does not measure the above categories directly, statements were created based upon these common characteristics of novice thinkers.

Many of the statements in the CLASS are not fully translatable to earth and ocean science because of the differences in the disciplines themselves. We have adapted many of the CLASS statements and developed new statements to produce a tool that probes the perceptions that are important to experts in the field of earth and ocean science. Similar to the CLASS, we designed the SPESS to work with all subdisciplines in the field of earth and ocean science (geology, geophysics, oceanography, and atmospheric science), and be accessible to people with varying degrees of knowledge toward the discipline, such as majors and nonmajors.

Results from the SPESS are being used to track how course and curriculum changes affect student perceptions. Pretest data can provide a snapshot of the student population at the beginning of the semester, so pedagogy and curriculum can be targeted towards preheld student perceptions. The SPESS can then be used to measure if these course and program changes positively affect student perceptions towards the discipline. Finally, specific cohorts of students can be tracked through a program to analyze how, when, and why their perceptions change.

\section{SURVEY DEVELOPMENT Design}

Faculty interviews and feedback were used to decide which statements from previous attitude/perception surveys were relevant to earth and ocean science and to identify additional perceptions important to earth and ocean science. Ten of the 29 statements in SPESS come directly from the CLASS-Phys (Adams et al., 2006) with the word "physics" replaced by "earth and ocean science." Many of the CLASSPhys statements deal with the use of mathematical equations, which faculty deemed were important to all the subdisciplines in earth and ocean science, although the use of equations varies across courses. Six come from the unpublished CLASS-Geo with the word "geoscience" replaced by "earth and ocean science" (J. Stempien, pers. comm.). Thirteen new statements were created based on faculty feedback. Previous versions of the survey were reworked by student interviews and expert validation to create the current version. Each statement has been validated to be concise, have one consistent interpretation, and be meaningful for even those with little to no knowledge of earth and ocean science.

\section{Early Versions}

The set of statements in the current survey is the product of multiple iterations starting with 46 statements. Initial interviews (as described below) with 14 novice students were used to identify ambiguous or confusing statements, or to clarify the wording in particular statements. Nine statements were completely discarded leaving 37 statements, some of which were slightly reworded.

The remaining 37 statements were then used to survey 28 experts (staff members and graduate students). These survey results were used to discard four additional statements where there was no clear expert agreement. Follow up interviews with experts and a realignment of the statements with the goals of the survey resulted in statements that were then revalidated below.

\section{Student Interviews: Current Version}

Eighteen students were interviewed to validate the current version of the survey. We selected six students that had never taken an earth and ocean science course before, six students that had taken one or more lower level earth and ocean science courses, but were majoring in another science discipline (applied science or arts), and six students that were taking higher level courses and majoring in the field of earth and ocean science. Lower level courses don't have pre-requisites and are taken either by students from other disciplines as electives to gain breadth or by majors as their introductory course. Higher-level courses are taken during the third and fourth years by students who are majoring in the discipline. This broad range of interviewees was obtained to test that the survey is accessible to all levels of students. 
The interviewees were paid student volunteers. Each student was initially asked some demographic information (age, major, favorite classes, career goal, etc.), both to ensure that the diverse population of the University of British Columbia (UBC) was represented and to make them more comfortable with the interview experience. Then, the student took the survey by pencil and paper. Finally, the survey was retaken verbally, with no access to the previous written answers. As the student answered the questions verbally, they were asked to explain their rationale to the interviewer. Most provided their rationale freely (without the interviewer having to ask again), and seemed comfortable with the situation. If they asked any questions of the interviewer, they were not answered until after the interview. Students were also asked to interpret the term "earth and ocean science" to ensure that it was consistent.

The interviews were audio recorded and transcribed shortly afterward. The transcribed interviews were compared with the initial pencil and paper test, to ensure that they aligned. It was found that $21 \%$ of the responses changed to a different one of the three groups of responses (disagree: 1 or 2 , neutral: 3 , and agree: 4 or 5). Of the students that changed their response, $83 \%$ were either to or from a neutral response, which aren't used in calculating the student's score on the survey (see the "Scoring" section below). Both the low percentage of changed responses and large number that involved neutral responses suggests that the consistency of the survey is sufficient. If the neutral responses are discarded, the reproducibility of the written answers is $96 \%$.

Listening to a verbal rationale from each student made it possible to determine whether their interpretation was consistent with the original intent of each question, and whether all students were interpreting the question in the same way. Those statements that were not interpreted in a way that was either consistent with the original intention and/or consistent between all students were either reworded or discarded.

One of the major changes that occurred over the course of the interviews was the use of the term "earth science." Many students felt that earth science only includes geology, and not geophysics, oceanography, or atmospheric science. In addition, simply using the word "science" elicited very different responses because most of the students were not limiting their thoughts to earth and ocean science, and were extending them to physics, chemistry, biology, mathematics, and so on. The term "earth and ocean science" was selected, as interviews showed that students consistently interpreted this term as a representation of the discipline. It should be noted that the validation of the term "earth and ocean science" only occurred at UBC in the Department of Earth and Ocean Sciences, which encompasses geology, geophysics, oceanography, and atmospheric science. However, we expect that the use of this term would still be successful in other contexts because few undergraduates, particularly at the lower levels (nonmajors) used in many of the interviews, have much sense of the subdisciplines mentioned above.

Half of the students were asked how they felt an expert in the field of earth and ocean science would respond on a select number of statements. All of the students interviewed about the expert response were completely aware of what the expert response was when asked, yet they always stated what they felt, which was often different than what they thought the expert would say.

\section{Expert Responses: Current Version}

Experts in our department (those holding a PhD in any subdiscipline of earth and ocean science) took the survey twice over the course of the validation, once for Version 1.5 (February 2008, $n=28$ ) and once for Version 3.5 (July 2009, $n=10)$. From Version 1.5 to Version 3.5, 10 statements remained the same, 4 statements were reworded, 20 new statements were created, and 22 statements were removed.

Experts were chosen to represent the breadth of our department, including geologists, geophysicists, oceanographers, and atmospheric scientists. These results defined the expert response used when scoring the survey. All questions that did not have a consistent expert response were removed from the survey.

\section{Evidence of Validity}

Using the above student interviews and expert responses, the SPESS has been validated to be interpreted consistently by all levels of students, to be accessible to all subdisciplines of earth and ocean science, and to distinguish between general populations who are expected to be placed differently on the novice-expert continuum (e.g., majors vs. nonmajors). Additionally, results from factor analysis, described later, show coherent groupings of statements into categories, and thus, statements that are clearly associated with one another.

Fall 2008 and fall 2009 responses from a large introductory general earth and ocean science course were compared for test-retest analysis. This compares survey responses between two administrations with similar incoming populations by calculating their correlation. Thus, it is a measure of the repeatability of the survey. Results are as follows: percentage favorable (agree) $=0.98$, percentage unfavorable (disagree) $=0.99$, and percentage neutral $=$ 0.89 . The high test-retest (correlation) values between fall 2008 and fall 2009 mean that responses given by different students from term to term are nearly identical, and the survey produces repeatable results with a consistent distribution. We have chosen to report the test-retest reliability because it supplies a measure of stability. Cronbach's alpha coefficient is often stated as evidence of reliability, but it actually measures internal consistency rather than stability. Internal consistency is a valuable measure for single construct assessments to help determine if in fact all the questions/statements are measuring the same construct. Since the SPESS is a multiple construct instrument, the Cronbach's alpha does not apply.

SPESS in its current version (V4.0) contains 29 Likert scale statements (5 point scale, strongly disagree to strongly agree; Likert, 1932), as well as both a Likert scale and free response question on personal interest.

\section{ADMINISTRATION}

The SPESS is completed online outside of class time once during the first two weeks of the term and again during the last two weeks of term. It takes the students approximately $10 \mathrm{~min}$ to complete in a thoughtful manner. A bonus of $1 \%$ is added to the grades of students who complete both the pre- and postsurvey, which greatly increases the number of responses. The average class response rate for the most recent run of the survey was $43.6 \%$, ranging from $10.8 \%$ to $64.0 \%$. Differences in 
response rate can most likely be attributed to the amount of advertisement and reminders that were given by instructors.

Since September 2007, more than 8,000 students at six institutions have taken the SPESS over the course of seven semesters. The four most recent semesters used the current and stable version of the survey. The mean age of students taking the survey is 20.5 years, with slightly more females $(54.4 \%)$ than males $(45.6 \%)$ enrolled in undergraduate programs at UBC (UBC Office of Planning and Institutional Research, 2010). In the first three semesters, classes participating were primarily first year courses open to both science and nonscience majors. In later semesters, more upper level courses that are specifically for earth and ocean science majors have been included. This allows us to track specific students through the program and differentiate between varying levels of students. Classes that have taken the SPESS span many subdisciplines of earth and ocean science including mineralogy, sedimentology, physical geology, oceanography, and atmospheric science. The most recent run of the survey (winter 2010) included 13 introductory classes for nonmajors (5 of them distance education), 5 introductory classes for majors, and 5 upper level classes for majors.

\section{SCORING}

To score the survey, we used the same method as other discipline-specific perception surveys have for ease of comparison. First, the scale is collapsed to a three point scale as it was found in interviews that the distinction between strongly agree and agree is different for each person due to differences in conservatism and confidence, consistent with results from Adams et al. (2006). Because of this differing interpretation, both "strongly agree" and "agree" and "strongly disagree" and "disagree" are collapsed into one point. Thus, there are three possible response groups: disagree, neutral, or agree.

In the case of the SPESS, the expert response for some of the statements is "disagree." and for others it is "agree." Thus, we score the responses by determining the percentage agreement and disagreement with the expert response for each statement, referred to as the percentage favorable and unfavorable. For example, if a class has a $65 \%$ favorable score in a category, this means that on average they have a $65 \%$ agreement with the expert (which could mean either disagreeing or agreeing with that particular statement). Because the selection of "neutral" occurs for variable reasons, the neutral responses are given no weight to the percentage favorable or unfavorable.

The filter question from the CLASS is incorporated to catch the students that randomly choose answers and do not read the statements. "We use this statement to discard the survey of people who are not reading the statements. Please select 'disagree' -option 2 (not 'strongly disagree') to preserve your answers." Before the data are analyzed, students who did not select option 2 are removed from the data set. Duplicate entries and those who selected the same option for most of the statements (greater than 65\%) are found and removed by manually searching the data.

Typically only students with both pre- and postdata are analyzed because we are interested primarily in the shift of perceptions between before and after taking a course. However, at times it is of interest to look at the full predataset, in order to better understand the incoming population.

\section{Categorization}

Both the pre- and postsurvey results from the fall 2008 and winter 2009 terms were analyzed using the reduced basis factor analysis method detailed by Adams et al. (2006). Factor analysis is a method commonly used in educational research that categorizes sets of statements by correlations apparent between responses to individual statements, and has been particularly utilized with attitudinal surveys (e.g., Gaothlobogwe et al., 2011). In both steps of the analysis, a principle components analysis with a direct oblimin rotation is used. First, an exploratory factor analysis (e.g., Schmitt and Sass, 2011) is performed, which produces a preliminary set of categories using all of the statements. Typically the first set of categories may contain a large amount of statements that are not very tightly grouped together, but works towards the final end product. Next, a reduced basis factor analysis is performed with one group of statements at a time (and often with many varied iterations) so that the weakly related statements do not skew the identification of specific categories (see Adams et al., 2006, for more detail). Statements may be shifted if they correlate better with other categories, and categories may be split into two if it is found that they are stronger as independents. We did not allow for less than three statements to be present in a category, as this would weight individual statements too heavily in the percentage favorable for that category. In total, this analysis produced seven final categories that we named to best represent the different aspects of student thought that they represented.

The strength of a category is represented by its robustness, calculated by an equation developed by Adams et al. (2006; Table I). This equation incorporates all of the factor analysis results that together represent statistical validity, including the correlation coefficients between statements, factor loadings, and scree plot results. The maximum possible value of the robustness is 10.00 .

The average of the robustness values for all the categories is 5.68. This value is lower than that of the CLASS-Phys (6.86) and the CLASS-Chem (7.30; Adams et al., 2006; Barbera et al., 2008). In comparison to both the CLASS-Phys and the CLASS-Chem, the SPESS does, however, contain fewer total statements, fewer statements in most of the categories, and no statements falling in multiple categories.

The percentage favorable is calculated both overall and for each of the seven individual categories. The Memorization category characterizes the extent to which students believe that earth and ocean science is about memorization of concepts, terms, and definitions (e.g., statement 2, "Understanding Earth and Ocean Sciences basically means being able to recall something you've read or been shown."). The Science and Society category describes how earth and ocean science relates to our society, in the media and in the government (e.g., statement 9, "Earth and Ocean Science predictions must be certain if we are to use them to make decisions that affect our society."). Mathematical Problem Solving includes those statements that discuss how problems are approached, and primarily addresses the use of equations and statistics in earth and ocean science (e.g., statement 12, "I do not expect equations to help my 
TABLE I: The average (between pre- and postdata) robustness of the categories and the statements contained within them.

\begin{tabular}{|l|c|c|}
\hline Category Name & Average Robustness & Statements \\
\hline Memorization & 6.32 & $2,7,15,22,24$ \\
\hline Science and Society & 6.24 & $9,17,27$ \\
\hline Mathematical Problem Solving & 5.24 & $8,12,19,23$ \\
\hline Personal Interest & 6.25 & $1,3,14,21,25$ \\
\hline Skeptical Reasoning & 4.66 & $4,6,16,26,28$ \\
\hline Conceptual Problem Solving & 5.28 & $11,13,29$ \\
\hline Human-Science Interaction & 5.80 & $5,10,20$ \\
\hline
\end{tabular}

understanding of Earth and Ocean Science ideas; they are just for doing calculations."). The Personal Interest category represents a student's curiosity towards, enjoyment of, and belief in the usefulness of earth and ocean science (e.g., statement 1, "Things that I see around me in nature often lead me to think about how the Earth works."). The amount and way that students self-check and search for information (e.g., discuss with other students, check the web, and investigate other sources) is described by the Skeptical Reasoning category (e.g., statement 4, "I investigate the source of the information on the web before I use it for an assignment"). The Conceptual Problem Solving category simply refers to whether or not students feel that they can make sense of the broad conceptual ideas in earth and ocean science, like how long landscapes take to form and how natural processes on earth work (e.g., statement 11, "I often don't really understand the underlying ideas behind how the Earth works"'). Human-Science Interaction describes human impacts on the environment, making decisions in life, and the interpretation of earth and ocean science information (e.g., statement 5, "Learning Earth and Ocean Sciences helps me understand the impacts humans have on the environment."). Only three of these categories have similar content to those found in the CLASS-Phys (Mathematical Problem Solving, Personal Interest, and Conceptual Problem Solving).

\section{RESULTS AND DISCUSSION}

At UBC in each of the individual courses we typically see overall percentage favorable scores in the $60 \%-65 \%$ range, with little to no positive change toward the end of term. This is a more positive result than has been seen with the CLASS-Phys, -Bio, and -Chem, which found a 5 to 10\% negative shift in their population of students (Adams et al., 2006; W. Adams, pers. comm.). Results from the CLASSPhys have shown a 5\% increase at best after targeting specific categorical results through pedagogy (Perkins et al., 2005).

We find that considering the results categorically is more interesting than considering an overall average (Table II). This average tends to blur the boundaries between different categories, and the categories themselves serve as a clear way to simplify the results when picking through each individual statement may not be desirable. For example, student perceptions related to Conceptual Problem Solving often show a large positive change (i.e., a shift towards more expert-like perceptions). We find that students as a whole are coming in with a low self-rated understanding of the earth (as many of the courses are first year courses) and are leaving with a greater sense of understanding. They also are leaving with a greater appreciation of problem solving strategies such as the use of equations and statistics. Memorization commonly shows a larger decrease than any other category (typically in the 3\%-5\% range). This suggests that, after taking a course in the department, students seem to feel more strongly that learning earth and ocean science is about memorization. Science and Society is most often the category with the lowest percentage favorable (both preand postsurvey) and typically shows little to no shift in a term, suggesting that these societal ideas are deeply entrenched or change on much longer timescales. Analyzing the SPESS scores in this way will be useful in targeting particular components of curricula or instruction.

TABLE II: Results from the winter 2009 term of an introductory general earth and ocean science class $(n=134)$.

\begin{tabular}{|l|c|c|c|}
\hline Category & $\begin{array}{c}\text { Pre \% Favorable } \\
\text { (Standard Error) }\end{array}$ & $\begin{array}{c}\text { Post \% Favorable } \\
\text { (Standard Error) }\end{array}$ & \% Shift (Standard Error) \\
\hline Overall & $60.3(1.5)$ & $61.3(1.7)$ & $1.0(1.4)$ \\
\hline Memorization & $69.5(2.3)$ & $66.4(2.6)$ & $-3.1(2.4)$ \\
\hline Science and Society & $29.9(2.5)$ & $28.9(2.7)$ & $-1.0(2.6)$ \\
\hline Mathematical Problem Solving & $54.0(2.6)$ & $55.6(2.9)$ & $1.6(2.5)$ \\
\hline Personal Interest & $70.4(2.4)$ & $73.5(2.5)$ & $3.0(2.2)$ \\
\hline Skeptical Reasoning & $57.9(2.5)$ & $57.6(2.6)$ & $-0.3(2.5)$ \\
\hline Conceptual Problem Solving** & $45.5(3.0)$ & $57.7(3.1)$ & $12.2(3.4)$ \\
\hline Human-Science Interaction & $85.3(2.2)$ & $82.8(2.2)$ & $-2.5(2.6)$ \\
\hline
\end{tabular}

${ }^{*} p<0.05,{ }^{* *} p<0.01$. 
TABLE III: Preterm results from the winter 2009 section of an upper level geology class for majors.

\begin{tabular}{|l|c|c|}
\hline Category & \% Favorable Male $(\mathrm{n}=17)$, SE in brackets & \% Favorable Female $(\mathrm{n}=21)$, SE in brackets \\
\hline Overall & $72.0(4.0)$ & $62.2(4.8)$ \\
\hline Memorization & $82.4(5.4)$ & $64.8(6.9)$ \\
\hline Science and Society & $47.1(9.1)$ & $47.6(6.7)$ \\
\hline Mathematical Problem Solving & $54.4(8.4)$ & $54.0(8.3)$ \\
\hline Personal Interest & $87.9(5.2)$ & $74.1(6.9)$ \\
\hline Skeptical Reasoning & $67.1(7.3)$ & $54.8(6.0)$ \\
\hline Conceptual Problem Solving & $68.6(8.3)$ & $69.8(6.9)$ \\
\hline Human-Science Interaction* & $88.2(4.0)$ & $68.3(8.1)$ \\
\hline
\end{tabular}

${ }^{*} p<0.05,{ }^{* *} p<0.01$.

When the predata are sorted by gender, classes at the lower levels show little to no difference between males and females in any of the categories. This differs from what was observed with the use of the CLASS in physics, biology, and chemistry. The CLASS-Phys, -Bio, and -Chem survey results all showed significantly different results between genders in the Personal Interest category (Adams et al., 2006; W. Adams, pers. comm.). They all found that females scored lower (sometimes in excess of 30\% lower) on this category (Adams et al., 2006).

However, as students progress onward through the earth and ocean science program, differences seem to emerge in upper level classes (Table III). Females have less expert views overall, particularly in the Memorization, Personal Interest, Skeptical Reasoning, and Human-Science Interaction categories, although only the Human-Science Interaction category shows a statistically significant difference between the two.

At this point we cannot be sure of where this difference originates, and why there is no difference between genders at the lower level. This could be attributed to students' prior experience with the discipline. In Canada, all students are introduced to physics, biology, and chemistry at the secondary level. However, earth science is not a required course, and at some schools it isn't even offered. It may be that students entering postsecondary and taking a course in earth and ocean science truly have very few preconceptions of the discipline, but as they continue to study it, they start to develop perceptions about the field of earth and ocean science. Further study of lower and upper level students including both SPESS scores and interviews would better inform this notion.

Many of our lower-level courses have a distance education version and a face-to-face version, with some distance education classes being better aligned to the faceto-face version than others. The main reason students listed for taking a distance education version of a class rather than the face-to-face version is that the face-to-face class did not fit into their schedule, they have a long commute, or that it gives them more flexibility. At the start of term, students in the distance education version have a lower personal interest than those in the face-to-face version, and it does not improve much by the end of term. This may be why students in the distance education version chose to take a course of that format in the first place.

The pre- to postsurvey shifts for distance education courses are often worse than for courses with an instructor in lecture (face-to-face; Table IV). The Memorization and Mathematical Problem Solving categories in particular show a large difference in shifts between the face-to-face and distance education version of the course. After taking the same course by distance education, students do not seem to be gaining the same problem solving expertise as those in the face-to-face version, and feel more strongly that earth and ocean science is about memorization.

Earth and ocean science majors (overall) show a higher preterm percentage agreement with the expert than nonmajors (in an introductory geology course) in all categories

TABLE IV: Results from the winter 2010 face-to-face $(\mathrm{FF}, N=130)$ and distance education $(\mathrm{DE}, N=195)$ versions of an introductory general earth and ocean science class.

\begin{tabular}{|c|c|c|c|c|c|c|}
\hline \multirow[t]{2}{*}{ Category } & \multicolumn{2}{|c|}{$\begin{array}{l}\text { Pre \% Favorable } \\
\text { (Standard Error) }\end{array}$} & \multicolumn{2}{|c|}{$\begin{array}{l}\text { Post \% Favorable } \\
\text { (Standard Error) }\end{array}$} & \multicolumn{2}{|c|}{$\begin{array}{c}\% \text { Shift } \\
\text { (Standard Error) }\end{array}$} \\
\hline & FF & $\mathrm{DE}$ & $\mathrm{FF}$ & $\mathrm{DE}$ & $\mathrm{FF}$ & $\mathrm{DE}$ \\
\hline Overall & $59.3(1.5)$ & $55.9(1.3)$ & $63.9(1.5)^{*}$ & $58.8(1.3)$ & $4.6(1.2)$ & $2.9(1.2)$ \\
\hline Memorization & $67.4(2.4)$ & $68.0(2.1)$ & $70.8(2.5)$ & $65.2(2.1)$ & $3.4(2.6)$ & $-2.8(2.0)$ \\
\hline Science and Society & $36.3(2.6)$ & $35.6(2.3)$ & $38.6(2.8)$ & $35.9(2.3)$ & $2.3(2.6)$ & $0.4(2.4)$ \\
\hline Mathematical Problem Solving & $47.1(2.8)$ & $48.0(2.4)$ & $56.3(2.7)^{*}$ & $48.8(2.4)$ & $9.2(2.5)^{*}$ & $0.9(2.3)$ \\
\hline Personal Interest & $71.9(2.5)^{*}$ & $64.9(2.1)$ & $75.6(2.2)^{*}$ & $67.7(2.1)$ & $3.7(2.5)$ & $2.8(2.0)$ \\
\hline Skeptical Reasoning & $57.5(2.3)^{*}$ & $51.0(2.0)$ & $58.6(2.5)$ & $54.5(2.0)$ & $1.1(2.4)$ & $3.6(2.2)$ \\
\hline Conceptual Problem Solving & $42.8(2.9)$ & $37.0(2.5)$ & $53.3(3.0)$ & $50.3(2.5)$ & $10.5(3.3)$ & $13.2(2.4)$ \\
\hline Human-Science Interaction & $83.3(2.2)$ & $79.3(1.8)$ & $87.7(2.0)$ & $84.9(1.8)$ & $4.4(2.4)$ & $5.6(2.2)$ \\
\hline
\end{tabular}

${ }^{*} p<0.05,{ }^{* *} p<0.01$ (comparison of each FF value with the DE value in the column immediately to the right) 
TABLE V: Preterm results from winter 2009 majors (overall) and nonmajors in an introductory geology course.

\begin{tabular}{|l|c|c|}
\hline Category & \% Favorable Majors $(\mathrm{n}=87)$, SE in brackets & \% Favorable Non-Majors (n=63), SE in brackets \\
\hline Overall** & $78.1(1.7)$ & $59.2(2.9)$ \\
\hline Memorization & $71.3(3.9)$ \\
\hline Science and Society** & $84.6(2.3)$ & $29.9(4.0)$ \\
\hline Mathematical Problem Solving** & $62.8(3.1)$ & $49.6(4.1)$ \\
\hline Personal Interest** & $71.7(2.8)$ & $65.9(4.3)$ \\
\hline Skeptical Reasoning & $91.0(1.4)$ & $58.1(3.9)$ \\
\hline Conceptual Problem Solving** & $67.0(3.1)$ & $49.5(4.2)$ \\
\hline Human-Science Interaction & $83.1(2.8)$ & $80.7(3.8)$ \\
\hline
\end{tabular}

${ }^{*} p<0.05,{ }^{* *} p<0.01$.

TABLE VI: Preterm results from winter 2010 introductory oceanography courses: UBC and a community college (CC).

\begin{tabular}{|l|c|c|}
\hline Category & \% Favorable UBC $(\mathrm{n}=86)$, SE in brackets & \% Favorable CC $(\mathrm{n}=33)$, SE in brackets \\
\hline Overall & $56.9(1.9)$ & $63.8(2.7)$ \\
\hline Memorization* & $66.6(3.1)$ & $79.4(4.4)$ \\
\hline Science and Society** & $31.6(3.1)$ & $51.5(5.0)$ \\
\hline Mathematical Problem Solving & $50.3(3.2)$ & $44.7(4.3)$ \\
\hline Personal Interest & $62.2(3.3)$ & $68.5(4.9)$ \\
\hline Skeptical Reasoning & $53.8(3.1)$ & $59.1(5.4)$ \\
\hline Conceptual Problem Solving & $45.6(3.6)$ & $53.5(5.0)$ \\
\hline Human-Science Interaction & $82.0(2.8)$ & $88.9(3.1)$ \\
\hline
\end{tabular}

${ }^{*} p<0.05,{ }^{* *} p<0.01$.

(e.g., Mathematical Problem Solving-71.7\% vs. 49.6\%; Table $\mathrm{V})$. The majors still have relatively low agreement in the Skeptical Reasoning category (67.0\%). However, a significant development in source checking may occur later in a person's career, such as during graduate school. Tracking a cohort of students all of the way through the program could better narrow down where exactly these changes occur, and how consistent they are.

Comparing similar introductory oceanography courses at UBC and a community college, we see more positive preterm responses at the community college in all but one of the categories (Table VI). Mathematical Problem Solving is the only category in which UBC students enter the class with more expert-like perceptions, meaning that they have a higher agreement with statements on equations and statistics and are more expert-like in their approaches to problem solving. The biggest differences between the community college students and UBC students are in the Memorization and Science and Society categories. Evidently more community college students believe that earth and ocean science is not so much about memorization but about understanding, and they are also more expert-like in the connections that they draw between earth and ocean science and the media and/or government. Involvement of multiple community colleges and large research institutions would increase the data pool for comparison, and interviews may help explain the differences.

\section{CONCLUSION}

The Student Perceptions about Earth Sciences Survey (SPESS) is a survey instrument designed and validated at a large research university to be used for determining students' perceptions about the discipline of earth and ocean science both before and after taking a course. Subsequently, the effect that pedagogical changes in earth and ocean science courses have on student perceptions can be determined. The SPESS builds off of the CLASS developed at the University of Colorado-Boulder (CU), with additions to encompass the needs of the field of earth and ocean science.

We have used the category selection method developed at CU, and find it useful for learning about different aspects of student perceptions before and after they take a course. This method produced seven categories within the SPESS, each characterizing a different aspect of student thought. The percentage agreement of student with expert response is first calculated overall, then within the seven categories in order to break down student level of expertise in different areas of the field.

Results show that overall, students in earth and ocean science at UBC enter their courses with approximately a $60 \%-65 \%$ agreement with the expert, but do not become much more expert-like after one term has finished. More detailed results include:

1. Students in earth and ocean science do not display the same gender differences at the lower level as similar surveys in physics, biology, and chemistry have shown, but differences do begin to emerge with higher-level courses. We speculate that this may be due to the fact that students have less exposure to earth science in secondary school compared to 
traditional sciences and therefore they developed less preconceptions.

2. The face-to-face version of a course often has more favorable shifts than its distance education counterpart. This may be due to the fact that students either self-select distance education classes because of lack of interest in the course, or they have a more positive or personalized experience in a face-to-face class.

3. Students who are earth and ocean science majors clearly show more expert-like views than those who are not majors. This is what we would expect from majors who choose to study earth and ocean science as opposed to students who are taking it for breadth requirements.

4. Data from an introductory oceanography course at a community college shows more expert-like results than seen with a similar course at UBC, especially with regards to memorization and connections between earth and ocean science and our society. There are many factors that could contribute to this result such as, class size, teaching philosophies, and maturity of students.

The SPESS is suitable for measuring and tracking student perceptions about earth and ocean science. Its purpose is to determine what postsecondary students think about the discipline and to learn more about the impact of specific courses, pedagogies, delivery methods, or curricula on student shifts toward or away from expert-like perceptions. Results can be used to inform instructional decisions and to monitor the impact of any changes made to courses. The SPESS has been completely validated, and is ready to be administered to earth and ocean science students at other institutions.

\section{Acknowledgments}

Thank you to Wendy Adams, Joshua Caulkins, Brett Gilley, Sara Harris, Francis Jones, and Carl Wieman for their comments on initial drafts of this paper and the project itself. Thank you also to the anonymous reviewers for their comments. This work is supported by the Carl Wieman Science Education Initiative (http://www.cwsei.ubc.ca) and Skylight UBC (http://www.skylight.science.ubc.ca).

\section{REFERENCES}

Adams, W.K., Perkins, K.K., Podolefsky, N.S., Dubson, M., Finkelstein N.D., and Wieman, C.E. 2006. New instrument for measuring student beliefs about physics and learning physics: the Colorado Learning Attitudes about Science Survey. Physical Review Special Topics-Physics Education Research, 2:1-14.

Aikenhead, G.S. and Ryan, A.G. 1992. The development of a new instrument: "Views on Science-Technology-Society" (VOSTS). Science Education, 76:477-491.

Barbera, J., Adams, W.K., Wieman, C.E., and Perkins, K.K. 2008. Modifying and validating the Colorado Learning Attitudes about Science Survey for use in chemistry. Journal of Chemical Education, 85:1435-1439.

Chi, M.T.H., Feltovich, P.J., and Glaser, R. 1981. Categorization and representation of physics problems by experts and novices. Cognitive Science, 5:121-152.

Fennema, E., and Sherman, J.A. 1976. Fennema-Sherman Mathematics Attitudes Scales: instruments designed to measure attitudes toward the learning of mathematics by females and males. Journal for Research in Mathematics Education, 7:324-326.

Gal, I., Ginsburg, L., and Schau, C. 1997. Monitoring attitudes and beliefs in statistics education. In Gal, I. and Garfield, J.B., eds. The assessment challenge in statistics education. Fairfax, VA: IOS Press, p. 37-51.

Gaothlobogwe, M., Laugharne, J., and Durance, I. 2011. The potential of multivariate analysis in assessing students' attitude to curriculum subjects. Educational Research, 53:65-83.

Hammer, D. 1994. Epistemological beliefs in introductory physics. Cognition and Instruction, 12:151-183.

Kitchener, K.S., and King, P.M. 1981. Reflective judgment: Concepts of justification and their relationship to age and education. Journal of Applied Developmental Psychology, 2:89116.

Larkin, J. 1983. The role of problem representation in physics. In Gentner, D. and Stevens, A., eds. Mental models. Hillsdale: Lawrence Erlbaum, p. 75-98.

Lederman, N.G., Abd-El-Khalick, F., Bell, R. L., and Schwartz, R. 2002. Views of nature of science questionnaire: Toward valid and meaningful assessment of learner's conceptions of nature of science. Journal of Research in Science Teaching, 39:497-521.

Libarkin, J.C. 2001. Development of an assessment of student conception of the nature of science. Journal of Geoscience Education, 49:435-442.

Libarkin, J.C., and Anderson, S.W. 2005. Assessment of learning in entry-level geoscience courses: Results from the Geoscience Concept Inventory. Journal of Geoscience Education, 53:394-401.

Likert, R., 1932. A technique for the measurement of attitudes. Archives of Psychology, 140:5-55.

Mao, S.L., and Chang, C.Y. 1998. Impacts of an inquiry teaching method on earth science students' learning outcomes and attitudes at the secondary school level. Proceedings of the National Science Council Part D, 8:93-101.

Perkins, K.K., Adams, W.K., Pollock, S.J., Finkelstein N.D., and Wieman, C.E. 2005. Correlating student beliefs with student learning using the Colorado Learning Attitudes about Science Survey. In Marx, J., Heron, P., and Franklin, S. eds. Proceedings of the 2004 Physics Education Research Conference. Sacramento, CA: American Institute of Physics, p. 61-64.

Schmitt, T.A., and Sass, D.A. 2011. Rotation criteria and hypothesis testing for exploratory factor analysis: Implications for factor pattern loadings and interfactor correlations. Educational and Psychological Measurement, 71:95-113.

Tai, R.H., Sadler, P.M., and Mintzes, J.J. 2006. Factors influencing college science success. Journal of College Science Teaching, 36:52-56.

UBC Office of Planning and Institutional Research (PAIR). 2010. Planning and Institutional Research. Available at http://pair. ubc.ca (accessed 4 August 2010).

\section{APPENDIX A}

Student Perceptions about Earth Sciences Survey (SPESS) Statements (V4.0)-University of British Columbia (Vancouver)

1. Things that I see around me in nature often lead me to think about how the Earth works.

2. Understanding Earth and Ocean Sciences basically means being able to recall something you've read or been shown.

3. When I look at a landscape, I sometimes try to figure out how it came to look that way.

4. I investigate the source of the information on the web before I use it for an assignment. 
5. Learning Earth and Ocean Sciences helps me understand the impacts humans have on the environment.

6. I compare what the media says about Earth and Ocean Science to how I think the Earth works.

7. In learning about the Earth, I usually memorize the definitions rather than make sense of the underlying ideas.

8. If I don't remember the answer to a question on an exam, there's nothing much I can do (legally!) to answer the question.

9. Earth and Ocean Science predictions must be certain if we are to use them to make decisions that affect our society.

10. Knowing about how the Earth works is useful in making some decisions in life.

11. I often don't really understand the underlying ideas behind how the Earth works.

12. I do not expect equations to help my understanding of Earth and Ocean Science ideas; they are just for doing calculations.

13. When I look at a landscape, I have an idea of how long it took to form.

\section{I enjoy learning Earth and Ocean Sciences.}

15. When studying Earth and Ocean Sciences, I relate the important information to what I already know rather than just memorizing it the way it is presented.

16. To understand Earth and Ocean Sciences I discuss it with other students.

17. If an Earth and Ocean finding is in the news, it means that it has been proven to be true.
18. We use this question to discard the survey of people who are not reading the statements. Please select "disagree"option 2 (not "strongly disagree") to preserve your answers.

19. I easily get lost when Earth and Ocean Science explanations involve probabilities or statistics.

20. Even when Earth and Ocean Science investigations are done correctly, the interpretation of the information that is discovered may change in the future.

21. The subject of Earth and Ocean Science has little relation to what I experience in the real world.

22. Spending a lot of time understanding why the Earth behaves the way it does is a waste of time.

23. Equations used in Earth and Ocean Science are another way to present ideas that we can describe in words.

24. To learn Earth and Ocean Sciences, I only need to memorize terms and their definitions.

25. I study Earth and Ocean Science to learn knowledge that will be useful in my life outside of school.

26. To understand Earth and Ocean Sciences, I sometimes think about my personal experiences and relate them to the topic being analyzed.

27. It is important for the government to approve new Earth and Ocean Science ideas before they can be widely accepted by the population.

28. When presented in class with a controversial Earth and Ocean Science idea on a topic I care about, I tend to check what other sources say on the topic.

29. I can usually make sense of how natural processes on Earth act. 